\title{
SELEÇÃO PRECOCE DE CLONES DE EUCALIPTO PARA AMBIENTES COM DISPONIBILIDADE DIFERENCIADA DE ÁGUA NO SOLO: RELAÇÕES HÍDRICAS DE PLANTAS EM TUBETES ${ }^{1}$
}

José Humberto Chaves ${ }^{2}$, Geraldo Gonçalves dos Reis ${ }^{3}$, Maria das Graças Ferreira Reis ${ }^{3}$, Júlio César Lima Neves ${ }^{4}$, José Eduardo Macedo Pezzopane ${ }^{5}$, Henrique Quero Polli ${ }^{6}$

\begin{abstract}
RESUMO - O presente trabalho objetivou identificar características em cinco clones de eucalipto crescendo em tubete plástico de $60 \mathrm{~mL}$, de modo a subsidiar a seleção precoce de material genético para plantios em ambientes com disponibilidade diferenciada de água no solo. Avaliaram-se a condutância estomática, a transpiração foliar, o potencial hídrico foliar e a fotossíntese líquida de plantas mantidas plenamente irrigadas e de plantas sob deficiência hídrica. Com a suspensão da irrigação, os clones 1250 e 1260 apresentaram menor condutância estomática e transpiração, produzindo ligeira diminuição nos valores de potencial hídrico foliar nas plantas. Observaram-se uma acentuada redução no potencial hídrico e abscisão foliar nos clones 0321 e 1277 , e, ao final de vários ciclos de seca, estes dois clones apresentaram as maiores taxas de fotossíntese líquida, em resposta à suspensão da irrigação. Com a re-irrigação, o clone 1277 emitiu, imediatamente, novas folhas, indicando sua capacidade de recuperação quando as condições hídricas do solo se tornam favoráveis. Esses resultados evidenciam que o clone 1277 deve tolerar ambientes sujeitos à deficiência hídrica.
\end{abstract}

Palavras-chave: Eucalipto, relações hídricas, seleção precoce.

\section{EARLY SELECTION OF EUCALYPT CLONES TO BE PLANTED IN ENVIRONMENTS WITH VARYING SOIL WATER AVAILABILITY: WATER RELATIONS OF PLANTS IN SMALL SIZE PLASTIC TUBES}

\begin{abstract}
This study was undertaken to identify physiological characteristics of cuttings from five eucalypt clones, growing in small plastic tubes $(60 \mathrm{~mL})$ to subsidize early selection for planting in sites with varying soil water availability. Stomatal conductance, leaf transpiration, leaf water potential and net photosynthesis of plants maintained fully irrigated and under water deficit were studied. The clones 1250 and 1260 presented reduction in stomatal conductance and leaf transpiration in water stressed plants, which maintained high leaf water potential. On the other hand, the clones 0321 and 1277 kept exhibiting high leaf stomatal conductance and transpiration and presented sharp decrease in leaf water potential under water stress condition. These two clones presented the highest net photosynthesis after several drying cycles. The clones 1277 presented a significant leaf abscission after the first drying cycle and a prompt recover after being re-watered, which indicates that this clone may tolerate dryer environments.
\end{abstract}

Key words: Eucalypts, water relations, early selection.

\footnotetext{
${ }^{1}$ Recebido para publicação em 01.10.2002 e aceito para publicação em 08.6.2004

${ }^{2}$ IBAMA, Brasília, DF.

${ }^{3}$ Professores do Departamento de Engenharia Florestal da UFV. <greis@ufv.br>. Bolsistas do CNPq.

${ }^{4}$ Professor do Departamento de Solos da UFV.

${ }^{5}$ Professor do Departamento de Engenharia Rural da UFES, Cx. Postal 16, 29500-000 Alegre, ES.

${ }^{6}$ Mestrando em Ciência Florestal da UFV.

Apoio: Copener Florestal Ltda., CNPq, FAPEMIG, CAPES.
} 


\section{INTRODUÇÃO}

A seleção de material genético de eucalipto é de interesse em sítios com acentuada variação de disponibilidade de água no solo. A seleção de material genético em diferentes condições de disponibilidade hídrica pode ser realizada através de testes de campo (GOMES, 1994; LELES et al., 1998), o que demanda um longo prazo até a avaliação final. É possível, no entanto, que a análise de características ecofisiológicas de plantas, ainda no estádio juvenil, produza resultados igualmente confiáveis, encurtando a extensão desses testes de campo.

Alguns trabalhos com mudas de eucalipto têm sido desenvolvidos sob diferentes condições de disponibilidadehídrica(FAÇANHA, 1983; RHODENBAUGH e PALLARDY, 1993; NAUTIYAL et al., 1994; STONEMAN et al., 1994; ROCHA e MORAES, 1997; TUOMELA, 1997; LI, 1998; GONÇALVES e PASSOS, 2000; LI et al., 2000; NGUGI et al., 2003). Tais trabalhos têm sido realizados em vasos que não restringem tão severamente o desenvolvimento das plantas quanto aos tubetes plásticos de tamanho reduzido $(60 \mathrm{~mL})$. Esses tubetes plásticos podem limitar a disponibilidade dos recursos de crescimento (REIS et al., 1989), fazendo com que as plantas os utilizem de maneira otimizada, o que pode possibilitar a seleção precoce de material genético. Ferreira et al. (1999) observaram variações no comportamento das plantas de Eucalyptus Citriodora (Corymbia citriodora (Hook.)K.D. Hill \& L.A.S. Jhonson) sob diferentes condições de disponibilidade hídrica, em tubetes, indicando a viabilidade de uso de plantas em recipientes de tamanho reduzido para obter respostas mais rápidas ao défice hídrico.

Na tentativa de obter a seleção precoce de clones de eucalipto, o presente estudo foi realizado em tubetes plásticos de pequeno tamanho, sob diferentes regimes de irrigação, visando identificar características fisiológicas, de modo a subsidiar o seu plantio em ambientes com disponibilidade variável de água no solo.

\section{MATERIAL E MÉTODOS}

Foram utilizadas mudas provenientes de miniestacas de cinco clones de eucalipto (0063, 0321, 1250, 1260 e 1277), produzidas pela COPENER FLORESTAL Ltda., localizada no norte do Estado da Bahia ( $11^{\circ} 51^{\text {' }}$ Latitude Sul e $38^{\circ} 27^{\prime}$ Longitude Oeste). As mudas foram produzidas em tubetes plásticos de aproximadamente $60 \mathrm{~mL}$, pelo método de miniestaquia, seguindo a metodologia tradicional utilizada pela empresa. $\mathrm{O}$ substrato empregado na produção das mudas foi constituído de vermiculita e composto orgânico à base de casca de coco, na proporção de 1:1. A escolha dos clones foi baseada nas suas respostas em plantios comerciais na empresa, estabelecidos em locais com níveis de precipitação pluviométrica variando de 700 a $1.200 \mathrm{~mm}$.

O experimento foi conduzido em casa de vegetação coberta com plástico transparente, no Viveiro de Pesquisas Florestais do Departamento de Engenharia Florestal da Universidade Federal de Viçosa, localizado no município de Viçosa, Minas Gerais (20\%45' Latitude Sul; $42^{\circ} 55^{\prime}$ Longitude Oeste e $690 \mathrm{~m}$ de altitude média).

Aos quatro meses após o início da produção das mudas, estas passaram por uma seleção, com vistas a obter mudas uniformes. O experimento foi constituído de 10 tratamentos, sendo dois níveis de irrigação e cinco clones, em esquema fatorial ( $2 \times 5)$, estabelecido em um delineamento inteiramente casualizado, com quatro repetições e 24 plantas por unidade experimental (U.E.). No primeiro nível de irrigação, as plantas foram mantidas irrigadas até a capacidade do tubete (plenamente irrigado), utilizando-se pelo menos duas irrigações diárias. No segundo nível de disponibilidade hídrica (estressado), a irrigação foi suspensa e somente reiniciada com o surgimento de sintomas de deficiência hídrica nas folhas da parte mediana da copa das plantas (intenso murchamento das folhas), completando-se cada ciclo de seca. Ao todo, as mudas foram submetidas a cinco ciclos sucessivos de seca.

Para auxiliar a determinação do final de cada ciclo de seca, foram realizados estudos preliminares com 36 mudas de cada um dos cinco clones, em laboratório. A irrigação foi suspensa após as mudas serem plenamente irrigadas e mantidas em um ambiente que apresentava elevada radiação solar difusa, no interior do laboratório, para que a depleção da umidade do substrato ocorresse lentamente. Durante seis dias consecutivos, foi medido, em seis plantas de cada clone, o potencial hídrico do antemanhã $(4 \mathrm{~h}-4 \mathrm{~h} 30$ da manhã) e determinada a umidade do substrato de cada planta, pelo método gravimétrico (EMBRAPA, 1997). O 
potencial hídrico do antemanhã mantém uma relação de equilíbrio com o potencial hídrico do substrato, em razão das baixas taxas transpiratórias apresentadas pelas plantas durante a noite. A redução do potencial hídrico do substrato foi associada ao aparecimento de sintomas de deficiência hídrica na planta, observado através de murchamento de suas folhas ao longo da curva de retenção de água do substrato. Dessa forma, foi possível calibrar os tratamentos de irrigação, identificando-se o final de cada ciclo, quando a irrigação seria reiniciada.

O experimento foi conduzido no período de 14 de dezembro de 1999 a 12 de janeiro de 2000 até que se completassem cinco ciclos sucessivos de seca. Entre os ciclos de seca, as plantas passaram por um período de recuperação de quatro a cinco dias, tendo sido mantidas irrigadas até a capacidade do tubete.

Durante todos os dias de cada ciclo de seca, foram medidas, ao longo do dia, em folhas totalmente expandidas da parte mediana da copa das plantas, a temperatura foliar, a condutância estomática e a transpiração foliar, com o porômetro de difusão de estado estacionário, modeloLI-1600 daLI-COR, às 9, 13 e 17hEssas medidas foram feitas na superfície abaxial da folha, sendo utilizadas três repetições de cada tratamento. Ao final de cada ciclo de seca, o potencial hídrico foliar foi determinado por meio de uma bomba de pressão (SCHOLANDER et al., 1965), em folhas totalmente expandidas, empregando-se três repetições de cada tratamento.

Após o último ciclo de seca, quando as plantas já haviam sido reirrigadas, foi feita a determinação da fotossíntese líquida a $800 \mu \mathrm{mol} \cdot \mathrm{m}^{-2} \cdot \mathrm{s}^{-1}$ de intensidade de radiação fotossinteticamente ativa, com um analisador de gases a infravermelho, portátil, modelo LI-6400 da LI-COR, entre 9 e $10 \mathrm{~h} 30$, para verificar a capacidade de recuperação da taxa fotossintética da planta. A escolha desse horário deveu-se ao fato de que as plantas apresentam máxima fixação de carbono nessa hora do dia, acentuando as respostas daquelas aos tratamentos de deficiência hídrica, o que foi observado em experimentos preliminares. Para essa medição foram utilizadas três repetições de cada tratamento, avaliando-se sempre folhas completamente expandidas, localizadas na parte mediana da copa da muda.

\section{RESULTADOS E DISCUSSÃO}

As plantas de todos os clones estudados não apresentaram diferença em condutância estomática nos tratamentos plenamente irrigado e sob deficiência hídrica, no decorrer dos vários ciclos de seca (Figura 1), embora os clones 0063, 0321 e 1277, no primeiro ciclo de seca, tenham apresentado tendência de maior condutância estomática no tratamento irrigado. Independentemente do clone, do tratamento de irrigação ou do ciclo de seca, as plantas apresentaram estômatos mais abertos às $9 \mathrm{~h}$, fechando-se parcialmente às $13 \mathrm{~h}$, permanecendo assim até às $17 \mathrm{~h}$.

Essas avaliações foram realizadas no período de verão, caracterizado por apresentar dias muito longos e quentes com elevada demanda evaporativa, mesmo à tarde $(17 \mathrm{~h})$. Dessa forma, as plantas mantiveram seus estômatos mais abertos apenas nas primeiras horas da manhã (9 h), quando a demanda evaporativa ainda era relativamente reduzida.

Os clones 0063, 0321 e 1277 mantiveram seus estômatos mais abertos em relação aos clones 1250 e 1260, nos dois níveis de irrigação, indicando menor consumo de água por esses últimos clones, quando suas plantas cresceram em tubetes plásticos de dimensões reduzidas.

Ao final de cada ciclo de seca, a condutância estomática das plantas submetidas à deficiência hídrica mostrou-se semelhante nos cinco clones, ou seja, independentemente do clone, os estômatos dessas plantas mantiveram-se parcialmente fechados. Por exemplo, na última leitura do primeiro ciclo de seca, às $13 \mathrm{~h}$ do segundo dia sob deficiência hídrica, as plantas com deficiência hídrica apresentaram condutância estomática de 25,$0 ; 26,8 ; 27,0 ; 26,1 ;$ e 27,3 mmol. $\mathrm{m}^{2} \mathrm{~s}^{-1}$. No entanto, no tratamento plenamente irrigado a condutância estomática variou de 29,5 a 60,4 mmol. $\mathrm{m}^{2} . \mathrm{s}^{-1}$. Esses resultados indicam haver diferenças entre clones quando as plantas são mantidas plenamente irrigadas. $\mathrm{O}$ fechamento parcial dos estômatos das plantas submetidas à deficiência hídrica promove a diminuição da perda de água por transpiração (SCHULZE, 1986; KOZLOWSKY e PALLARDY, 1996).

No último ciclo de seca, as plantas dos clones 0321 e 1277, submetidas ao défice hídrico, tenderam a manter seus estômatos mais abertos em relação às plantas plenamente irrigadas às $9 \mathrm{~h}$ dos dois dias do 
Primeiro ciclo de seca
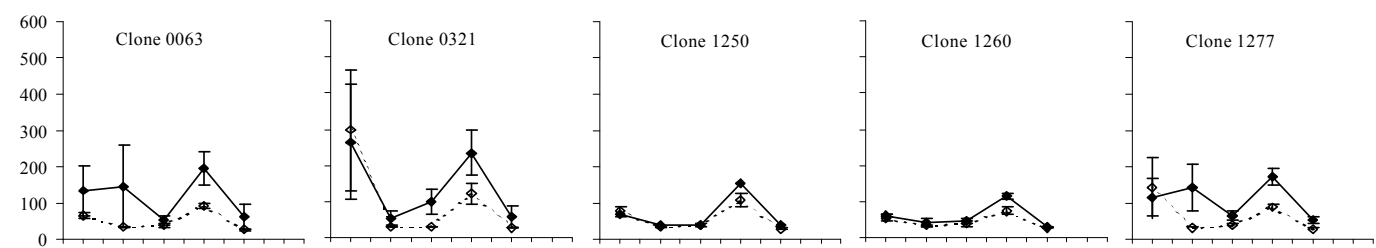

Segundo ciclo de seca
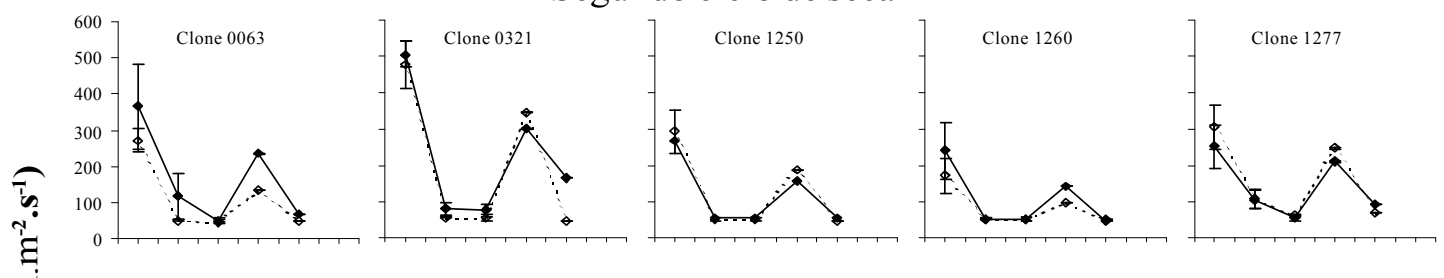

Terceiro ciclo de seca
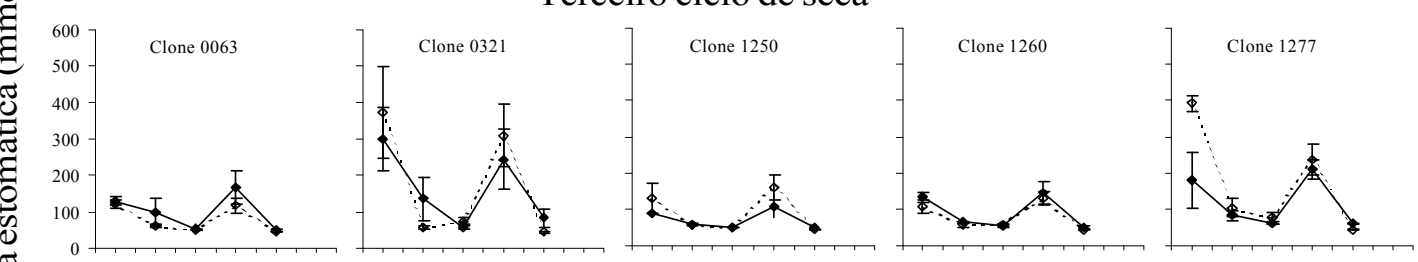

Quarto ciclo de seca
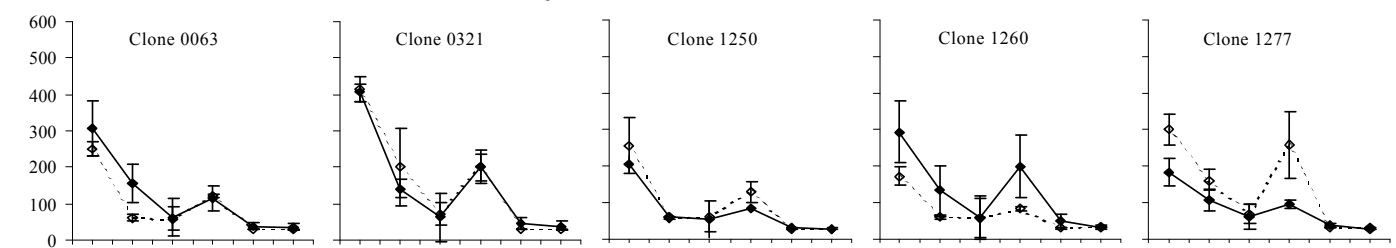

Quinto ciclo de seca
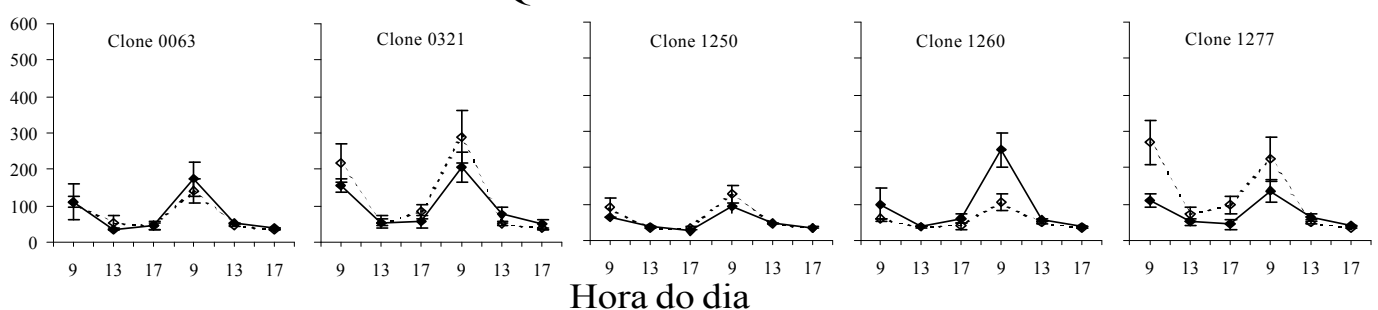

Figura 1 - Condutância estomática de plantas de cinco clones de eucalipto crescendo em tubetes nos tratamentos plenamente irrigado $(\multimap$ ) e estressado ( $\diamond-\cdots)$, nos cinco ciclos de seca (as barras referem-se ao erro-padrão da média de três plantas).

Figure 1 - Stomatal conductance of plants of five eucalypt clones growing in plastic tubes on well watered ( $\rightarrow)$ and water stressed $(\cdots, \ldots . .$.$) treatments, in five drying cycles (the bars are standard errors of three plants).$

ciclo. Esses dois clones apresentaram intensa redução na área foliar em resposta ao défice hídrico. Dessa forma, apesar desses clones possuírem estômatos mais abertos, o consumo de água, após experimentar vá- rios ciclos de seca, foi menor ao final, em razão de apresentarem menor superfície transpiratória. Diante disso, a abscisão foliar pode ser uma estratégia de adaptação, possibilitando as plantas desses clones, 
quando submetidas à acentuada deficiência hídrica, reduzirem rapidamente sua superfície transpiratória e, por conseqüência, o uso de água (POOK, 1985; LARCHER, 1995). Essa área foliar foi rapidamente recomposta assim que se realizou a reirrigação.

Os clones 1250 e 1260 mantiveram seus estômatos mais fechados em relação aos demais, em todos os ciclos de seca, indicando haver menor consumo de água pelas plantas desses clones, no caso de limitação de água no solo.

O quarto e o quinto ciclo de seca foram os mais longos, em comparação com os três primeiros ciclos, estendendo-se até as $17 \mathrm{~h}$ do segundo dia em que a irrigação havia sido suspensa. Essa resposta indica que houve adaptação dos clones ao défice hídrico, através de um melhor controle estomático. Após experimentar vários ciclos de deficiência hídrica, as mudas de eucalipto podem apresentar adaptações relativas ao controle estomático (REIS et al., 1988). Além disso, a perda de área foliar de alguns clones sob deficiência hídrica pode explicar a perda de água mais lenta no substrato durante os últimos ciclos de seca.

A transpiração foliar (Figura 2) seguiu a mesma tendência de comportamento da condutância estomática. Essa resposta também tem sido observada por alguns autores (GOMES, 1994; MIELKE et al., 1999), uma vez que a transpiração se dá, principalmente, pela perda de água através dos estômatos (KRAMER e BOYER, 1995). Não foi observada diferença na transpiração foliar entre as plantas plenamente irrigadas e sob deficiência hídrica, embora tenha havido diferenças significativas entre os diversos clones e nos diferentes ciclos de seca. No primeiro ciclo de seca, verificouse uma tendência de maior transpiração nas plantas plenamente irrigadas em comparação com aquelas sob deficiência hídrica. No quarto e quinto ciclos de seca, as diferenças entre os dois tratamentos de irrigação foram menores, sendo observado, nos clones $0321 \mathrm{e}$, principalmente, para o 1277 , uma tendência de transpiração maior nas plantas com deficiência hídrica em relação às do tratamento plenamente irrigado.

As plantas submetidas ao défice hídrico apresentaram queda no potencial hídrico foliar ao final dos ciclos de seca, variando de -0,8 MPa no clone 1250 a $-1,98 \mathrm{MPa}$ no clone 1277 , nas plantas submetidas à deficiência hídrica, enquanto nas plantas plenamente irrigadas o potencial hídrico foliar variou de $-0,25$ a $-0,35 \mathrm{MPa}$ (Figura 3). Resultado semelhante foi constatado por Reis et al. (1988), em que mudas deE. grandis W. Hill ex Maiden e E. camaldulensis Dehnh., crescidas em tubetes, exibiram potenciais hídricos foliares próximos de $-2,0 \mathrm{MPa}$ após o surgimento de sintomas drásticos de murcha foliar.

Segundo Kozlowski e Pallardy (1996), plantas sob défice hídrico acentuado quase sempre apresentam células não completamente túrgidas e potencial hídrico substancialmente menor que zero. Os primeiros efeitos visíveis do défice hídrico foram a paralisação do crescimento, fechamento dos estômatos e murchamento das folhas jovens. Ao final de cada ciclo, o abaixamento do potencial hídrico foi acompanhado por esses efeitos, indicando que o nível de estresse hídrico a que as plantas se submeteram foi adequado para a avaliação desses clones.

O clone 1250 mostrou-se mais conservativo, mantendo seus estômatos parcialmente fechados ao longo do dia e, ao longo de todos os ciclos de seca, vindo a apresentar menor consumo de água (Figura 2). Porém, o clone 1277 sofreu redução de área foliar. Além da diminuição na perda de água, é possível que as plantas desse clone tenham apresentado algum controle osmótico em razão de se ter observado menor redução no seu potencial hídrico foliar (Figura 3).

Segundo Larcher (1995), uma boa parte dos processos vitais em plantas é afetada pelo declínio do potencial hídrico. A deficiência hídrica pode produzir decréscimo no volume celular, aumento na concentração do conteúdo celular e progressiva desidratação do protoplasma.

As plantas sob deficiência hídrica apresentaram, em geral, ao final dos cinco ciclos de seca, taxa de fotossíntese líquida maior do que aquela observada nas plantas plenamente irrigadas, exceto no clone 1250 (Figura 4). As avaliações de fotossíntese líquida foram realizadas quatro dias após o último ciclo de seca, com as plantas plenamente irrigadas.

Mesmo nessas condições em que as plantas experimentaram uma seqüência de ciclos de seca, após a retomada da irrigação, parece não ter havido efeito detrimental do défice hídrico sobre o aparelho fotossintético das folhas em que foram feitas as medições e que o tempo entre o fim do défice hídrico e a medição da fotossíntese foi suficiente para que as plantas recuperassem a sua capacidade fotossintética. Segundo

R. Árvore, Viçosa-MG, v.28, n.3, p. 333-341, 2004 

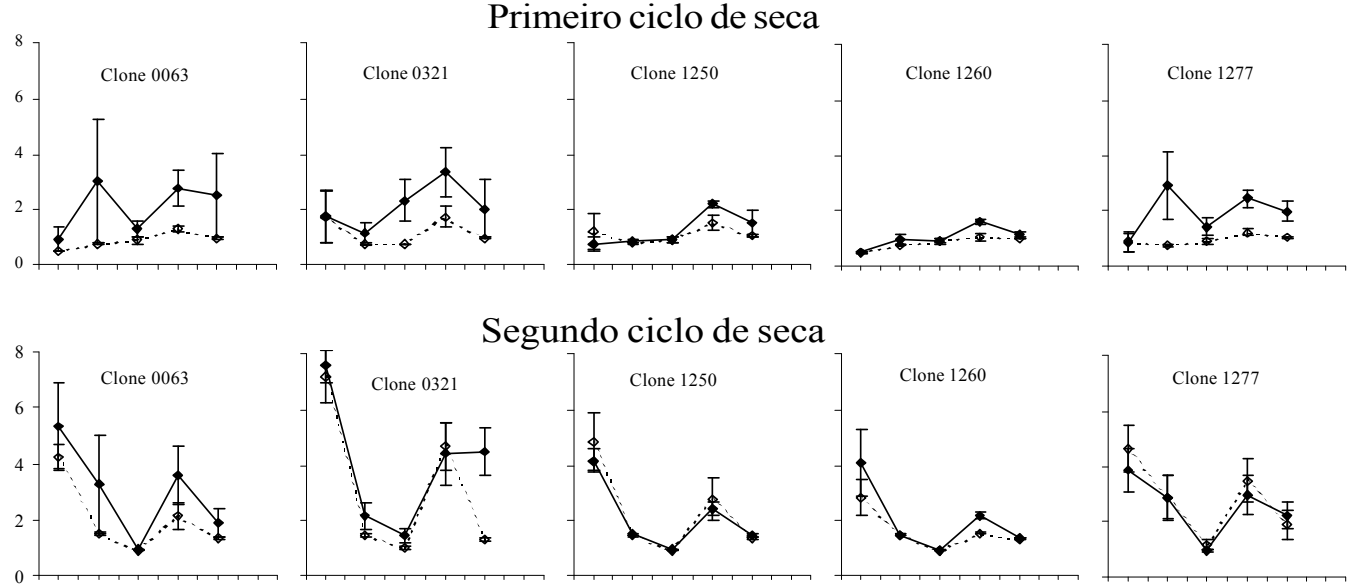

Segundo ciclo de seca
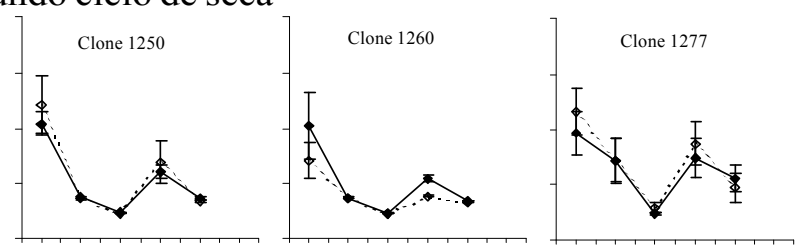

Terceiro ciclo de seca
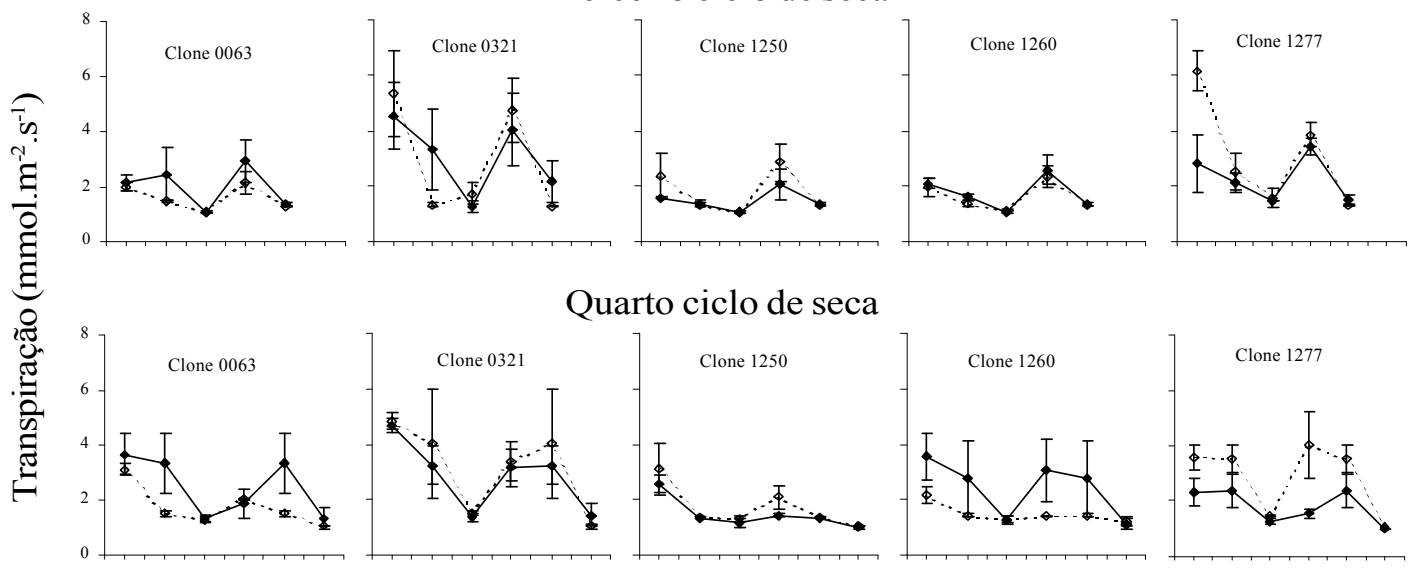

Quarto ciclo de seca
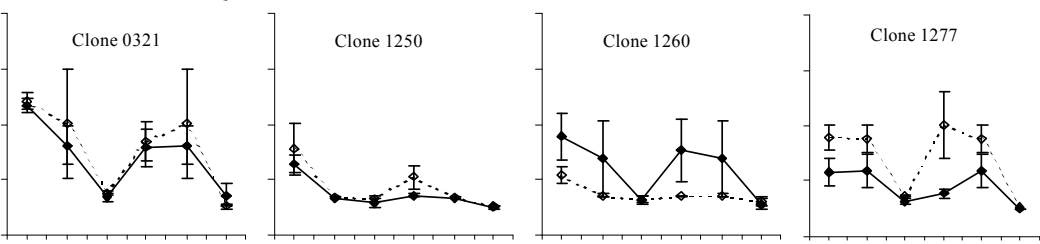

Quinto ciclo de seca
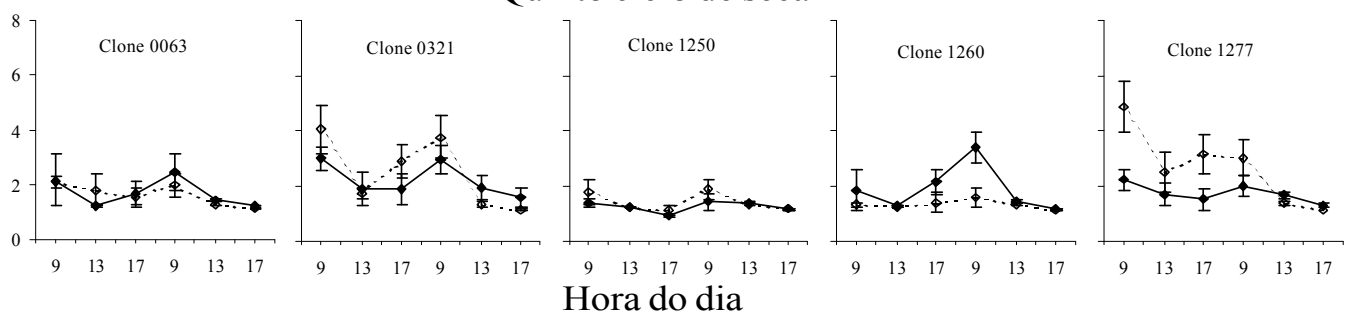

Figura 2 - Transpiração foliar de plantas de cinco clones de eucalipto crescendo em tubetes nos tratamentos plenamente irrigado $(\multimap)$ e estressado $(-\diamond-\cdots)$, nos cinco ciclos de seca (as barras referem-se ao erro-padrão da média de três plantas).

Figure 2 - Leaf transpiration of plants of five eucalypt clones growing in plastic tubes on well watered $(\rightarrow-)$ and water stressed $\left(-\diamond_{-\infty}\right)$ treatments, in five drying cycles (the bars is the standard errors of three plants).

Kozlowski e Pallardy (1996), a recuperação das plantas após sua exposição à deficiência hídrica severa pode demandar vários dias, dependendo da severidade e duração dessa deficiência e da capacidade das plantas de recuperar a sua capacidade fotossintética, e estar associada à sua resistência ao défice hídrico.

Durante o período em que as plantas são submetidas à deficiência hídrica, a fotossíntese é redu- 


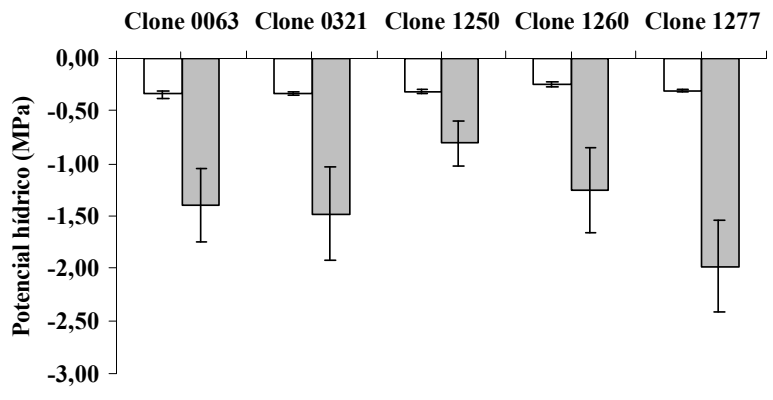

$\square$ Irrigado $\square$ Estressado

Figura 3 - Potencial hídrico foliar de plantas de cinco clones de eucalipto crescendo em tubetes sob diferentes regimes hídricos - média dos cinco ciclos de seca (as barras referem-se ao erro-padrão da média de cinco plantas).

Figure 3 - Leaf water potential of five eucalypt clones growing in plastic tubes under different water regimes mean of five drying cycles (the bars are standard errors of five plants).

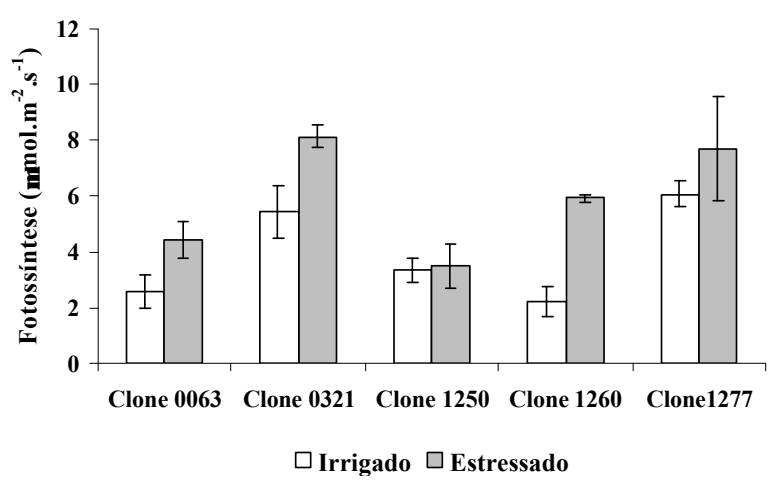

Figura 4 - Fotossíntese líquida de plantas de cinco clones de eucalipto crescendo em tubetes de $60 \mathrm{ml} \mathrm{sob}$ diferentes regimes hídricos, ao final de cinco ciclos subseqüentes de seca (as barras referem-se ao erropadrão da média de três plantas).

Figure 4-Net photosynthesis of plants of five eucalypt clones growing in plastic tubes under different water regimes, after five sequential drying cycles (the bars is the standard errors of three plants).

zida em razão do fechamento dos estômatos ou da interferência no processo fotossintético (KAISER, 1987; REID et al., 1991; KOZLOWSKI e PALLARDY, 1996). Stoneman et al. (1994), submetendo mudas de $E$. marginata a ciclos sucessivos de seca, avaliaram a sua fotossíntese durante e após o período de défice hídrico. As plantas apresentaram, no período de défice hídrico, redução drástica na taxa fotossintética, recuperando os valores de fotossíntese dois dias após a reirrigação.

No presente estudo, ao final dos cinco ciclos de seca, as plantas que foram submetidas à deficiência hídrica apresentaram área foliar menor do que as do tratamento plenamente irrigado, em razão da abscisão foliar provocada pelo défice hídrico. Dessa forma, as plantas anteriormente submetidas a défice hídrico aumentaram sua taxa fotossintética líquida por unidade de área foliar, para promover a retomada do crescimento.

Observaram-se, nas plantas plenamente irrigadas, sintomas de deficiência nutricional, principalmente de nitrogênio e potássio. Esses sintomas não foram observados com a mesma intensidade nas plantas submetidas à deficiência hídrica. Dessa forma, acredita-se ter havido, em razão do défice hídrico, maior ciclagem interna de alguns nutrientes, das folhas senescentes (fonte) para as folhas em crescimento ativo (dreno). No entanto, nas plantas plenamente irrigadas pode ter havido lixiviação de nutrientes nos tubetes. Esses fatos poderão, também, explicar a maior taxa de fotossíntese líquida exibida pelas plantas submetidas à deficiência hídrica. Os clones 0321 e 1277 sofreram elevada abscisão foliar, tendo, porém, apresentado valores mais elevados de fotossíntese líquida nas folhas remanescentes da planta.

A menor diferença observada na taxa de fotossíntese líquida entre os tratamentos plenamente irrigado e estressado foi verificada no clone 1250 , com valores de 3,34 e 3,50 $\mu$ mol. $\mathrm{m}^{-2} . \mathrm{s}^{-1}$, respectivamente. Esse foi, também, o clone menos afetado pelo défice hídrico, inclusive apresentando menor taxa de abscisão foliar. Esses resultados indicam que o défice hídrico favoreceu, de alguma maneira, o aumento na taxa fotossíntese líquida após a reirrigação desses clones.

Os resultados evidenciam a necessidade de estudar esses clones em estádios mais avançados de desenvolvimento e em recipientes de maiores dimensões, de modo a identificar outras características que indicam adaptação a ambientes com disponibilidade variável de água no solo.

R. Árvore, Viçosa-MG, v.28, n.3, p. 333-341, 2004 


\section{CONCLUSÕES}

Os clones estudados apresentaram diferentes adaptações em ambientes com disponibilidade variável de água no solo. Os clones 1250 e 1260 exibiram, de modo geral, menor condutância estomática e transpiração, indicando menor consumo de água.

Os clones 0321 e 1277 sofreram redução no potencial hídrico nas plantas sob deficiência hídrica, em razão da maior condutância estomática e transpiração, tendo apresentado elevada abscisão foliar durante o ciclo de seca. Essa abscisão foliar pode ser uma estratégia de adaptação das plantas desses clones a ambientes com limitação de água no solo.

A maior taxa fotossintética líquida nas plantas desses dois clones após a reirrigação pode indicar rápida recuperação do crescimento após ciclos de seca, evidenciando que ambos são mais indicados para plantio em áreas de solo com elevada deficiência hídrica.

\section{REFERÊNCIAS BIBLIOGRÁFICAS}

\section{EMPRESA BRASILEIRA DE PESQUISA}

AGROPECUÁRIA - Centro Nacional de Pesquisa de Solos - EMBRAPA/CNPS. Manual de métodos de análise de solo. 2. ed. Rio de Janeiro: 1997. $212 \mathrm{p}$.

FAÇANHA, J.G.V. Aspectos fisiológicos do crescimento de Eucalyptus spp. submetidos a deficiência hídrica . 1983. 47f. Dissertação (Mestrado em Fisiologia Vegetal) - Universidade Federal de Viçosa, Viçosa, 1983.

FERREIRA, C.A.G.; DAVIDE, A.C.; CARVALHO, L.R. Relações hídricas em mudas de Eucalyptus citriodora Hook., em tubetes, aclimatadas por tratamentos hídricos. Cerne, v. 5, n. 2, p. 95-104, 1999.

GOMES, R.T. Efeito do espaçamento no crescimento e nas relações hídricas de Eucalyptus spp. na região de cerrado de Minas Gerais. 1994. 85f. Dissertação (Mestrado em Ciência Florestal) - Universidade Federal de Viçosa, Viçosa, 1994.

GONÇALVES, M.R.; PASSOS, C.A.M. Crescimento de cinco espécies de eucalipto submetidas a déficit hídrico em dois níveis de fósforo.

Ciência Florestal, v. 10, n. 2, p.145-161, 2000.
KAISER, W.M. Effects of water deficit on photosynthetic capacity. Physiologia Plantarum, v. 71, p. 142-149, 1987.

KOZLOWSKI, T.T.; PALLARDY, S.G.

Physiology of woody plants. 2. ed. San Diego: [s.n.], 1996. 411 p.

KRAMER, P.J.; BOYER, J.S. Water relations of plants and soils. San Diego: [s.n.], 1995. $495 \mathrm{p}$.

LARCher, W. Physiological plant ecology. 3. ed. New York: [s.n.], 1995. 506 p.

LELES, P.S.S. et al. Relações hídricas e crescimento de árvores de Eucalyptus camaldulensis e Eucalyptus pellita sob diferentes espaçamentos na região de cerrado. Revista Árvore, v. 22, n. 1, p. 41-50, 1998.

LI, C. Some aspects of leaf water relations in four provenances of Eucalyptus microtheca seedlings. Forest Ecology and Management, v. 111, n. 2-3, p. 303-308, 1998.

LI, C. et al. Drought responses of Eucalyptus microtheca provenances depend on seasonality of rainfall in their place of origin. Australian Journal of Plant Physiology, v. 27, n. 3, p. 231-238, 2000.

MIELKE, M.S. et al. Stomatal control of transpiration in the canopy of a clonal Eucalyptus grandis plantation. Trees: Structure and Function, v. 13, p. 152-160, 1999.

NAUTIYAL, S. et al. Plant responses to water stress: changes in growth, dry matter production, stomatal frequency and leaf anatomy. Biologia Plantarum, v. 36, n. 1, p. 91-97, 1994.

NGUGI, M.R. et al. Leaf water relations of Eucalyptus cloeziana and Eucalyptus argophloia in response to water deficit. Tree Physiology, v. 23, p. 335-343, 2003.

POOK, E.W. Canopy dynamics of Eucalyptus maculata Hook. Effects of drought. Australian Journal of Botany, v. 33, n. 1, p. 65-79, 1985. 
REID, D.M.; BEALL, F.D.; PHARIS, R.P. Environmental cues in plant growth and development. In: STEWARD, F.C. Plant physiology: a treatise. San Diego: Growth and Development, 199. v. 10, p. 65-181.

REIS, G.G.; REIS, M.G.F.; MAESTRI, M. Crescimento e relações hídricas de mudas de Eucalyptus grandis e E. camaldulensis em tubetes sob três regimes de irrigação. Revista Árvore, v. 12, n. 2, p. 183-195, 1988.

REIS, G.G. et al. Crescimento de Eucalyptus camaldulensis, E. grandis e E. cloeziana sob diferentes níveis de restrição radicular. Revista Árvore, v. 13, n. 1, p. 1-18, 1989.

RHODENBAUGH, E.G.; PALLARDY, S.G. Water stress, photosynthesis and early growth patterns of cuttings of three Populus clones. Tree Physiology, v. 13, n. 3, p. 213-226, 1993.
ROCHA, A.M.S.; MORAES, J.A.P.V. Influência do estresse hídrico sobre as trocas gasosas em plantas jovens envasadas de Stryphnodendron adstringens (Mart.) Coville. Revista Brasileira de Fisiologia Vegetal, v. 9, n. 1, p. 41-46, 1997.

SCHOLANDER, P.F. et al. Sap pressure in vascular plants. Science, v. 148, p. 339-346, 1965.

SCHULZE, E.D. Whole-plant responses to drought. Australian Journal of Plant Physiology, v. 13, n. 1, p. 127-141, 1986.

STONEMAN, G.L.; TURNER, N.C.; DELL, B. Leaf growth, photosynthesis and tissue water relations of greenhouse-grown Eucalyptus marginata seedlings in response to water deficits. Tree Physiology, v. 14, n. 6, p. 633-646, 1994.

TUOMELA, K. Leaf water relations in six provenances of Eucalyptus microtheca: a greenhouse experiment. Forest Ecology and Management, v. 92, n. 1-3, p. 1-10, 1997. 